\title{
A Numerical Study on Performance of Dental Air Turbine Handpieces
}

\author{
B. BEIGZADEH*, S. DERAKHSHAN**, D. ZIA SHAMAMI* \\ *School of Mechanical Engineering, Iran University of Science and Technology, Iran, Email: b_beigzadeh@iust.ac.ir \\ **School of Mechanical Engineering, Iran University of Science and Technology, Iran, Email: shderakhshan@iust.ac.ir \\ ***School of Mechanical Eng., Iran Univ. of Science and Technology, Iran, Email: darushshamami@mecheng.iust.ac.ir \\ cross $^{\text {ref }}$ http://dx.doi.org/10.5755/j01.mech.23.5.15477
}

\section{Introduction}

Dental air turbine handpiece has evolved significantly over the years and it remains a vital part of dentistry today. It has been widely used in clinical dentistry as the main cutting tool for more than 50 years [1]. The handpiece is a standard instrument in dentistry that is used to remove carries, cavity preparation, tooth tissue grinding and most dental cutting practices [2] which could have effective role in dental remedial operations [3-4]. The source of rotation power is to convert high pressure air into mechanical work via a micro rotor. The rotor blades rotate at high speed, and the bur is applied to the teeth. Usually, high speed air-turbine dental handpieces operate at 200,000 to 400,000 revolutions per minute [5]. The main part of the dental air turbine is its high speed rotor head consisting of a casing with air inlet and outlet nozzles, impeller, spindle, chuck and bearings in millimeter size, as shown in Fig. 1. The most important factors to determine the air turbine performance and to improve the efficiency are speed, torque and power. Experimental determination of the dental air turbine characteristics such as free running speed, torque, power and bearing resistance have been carried out in detail by Brockhurst et al. [1] and Dyson et al. [6-7]. Some of researchers studied the vibration characteristics of dental high-speed turbines [8]. Seto investigated the influence of further design factors, e.g. air inlet and outlet diameters and spacer thickness on dental turbine performance with an experimental testing system [9]. Juraeva et al. presented an optimum blade shape of the air turbine that maximizes the torque using the design of experiments (DOE) [5]. Muller et al. performed a parameter performance study on an air turbine for a high frequency air bearing spindle by computational fluid dynamic (CFD) [10]. Chiang et al. [11] and Hsu et al. [12] focused on the turbine blade and the flow channel designs using CFD simulations and experiments. Wei et al. studied the influence of various factors on dental handpiece's bearing failure [13].

The high speed rotor head is one of the key components of dental air turbines. There are some studies which numerically investigated the influence of the Air turbine blade shape and flow channel design on the turbine performance [10-11]. Although there exist many studies on optimizing blades of other kind of turbo-machinery apparatus [14], however, there is no comprehensive study on pressure, temperature and air density distribution in the casing and applied forces to the impeller in dental handpieces. Therefore, the purpose of this study is to evaluate the effects of air inlet pressure and the key design parameters on the torque, the air distribution characteristics that noted and the applied forces to the impeller using 3D finite volume analysis.

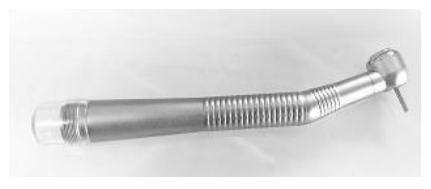

a

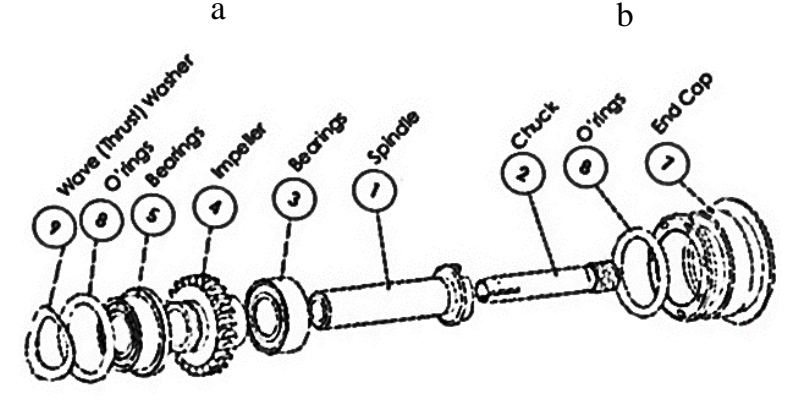

c

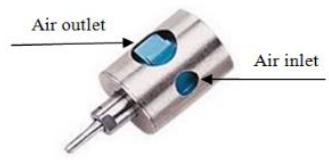

b
Fig. 1 (a) The dental air turbine handpiece (b) the rotor head (c) the cartridge components [15]

Table 1

The specifications of three cartridges

\begin{tabular}{|c|c|c|c|c|c|}
\hline Name & $\begin{array}{c}\text { Impeller } \\
\text { diameter, } \\
\mathrm{mm}\end{array}$ & $\begin{array}{c}\text { Inlet di- } \\
\text { ameter, } \\
\mathrm{mm}\end{array}$ & $\begin{array}{c}\text { Outlet di- } \\
\text { ameter, } \\
\mathrm{mm}\end{array}$ & $\begin{array}{c}\text { Angle of } \\
\text { inlet noz- } \\
\text { zle, deg }\end{array}$ & $\begin{array}{c}\text { Gap, } \\
\mathrm{mm}\end{array}$ \\
\hline Type 1 & 7.6 & 1.5 & 2 & 10 & 0.2 \\
\hline Type 2 & 9.8 & 1.5 & 2 & 10 & 0.2 \\
\hline Type 3 & 10.4 & 2 & 2.7 & 10 & 0.27 \\
\hline
\end{tabular}

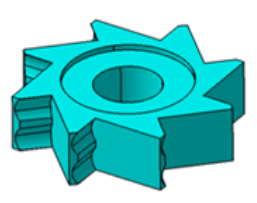

(a) type 1

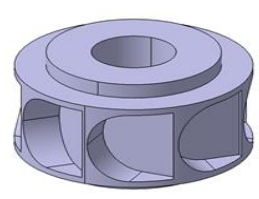

(b) type 2

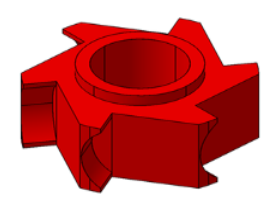

(c) type 3
Fig. 2 3D models of three impellers

\section{Modelling}

Three impeller samples used in commercial dental turbines (as listed in table 1) have been selected to be modeled and utilized for simulation purposes. In order to achieve an accurate modeling, first of all, the turbine handpieces have been disassembled, and the impellers are 3D scanned using a digitizer apparatus (Renishaw Company, model: Cyclone2). Then, the outputs are handled using CATCAM software to generate corresponding 3D models (Fig. 2). 


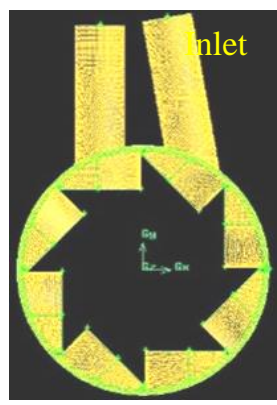

a

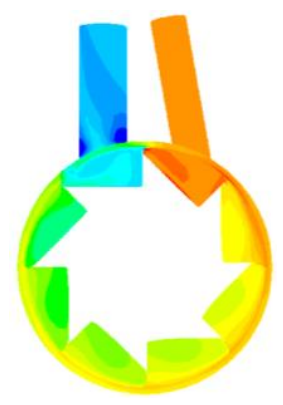

b

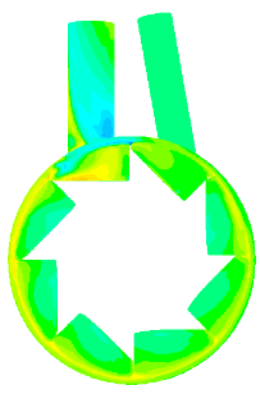

c

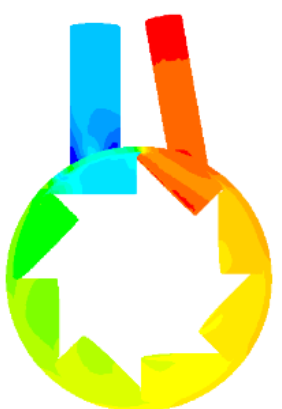

d

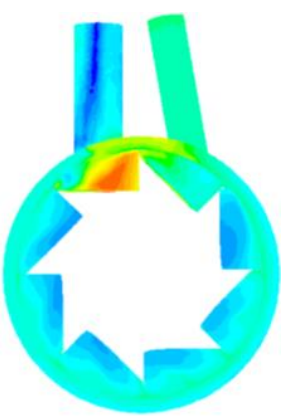

Fig. 3 (a) Fluid geometry and grid system for computation; (b) Distribution of air pressure; (c) Distribution of air temperature; (d) Distribution of air density; (e) Temperature distribution in the cartridges with the gap of $5.0 \mathrm{~mm}$

\section{Governing equations}

In this study, GAMBIT 2.4.6 and FLUENT 6.3.26 have been used to generate grid and to solve governing equations, respectively. The governing equations of fluid flow in the cartridge (around the impeller) include continuity, momentum and energy equations. Continuity equation for a compressible fluid is as follows:

$$
\frac{\partial \rho}{\partial t}+\frac{\partial(\rho u)}{\partial x}+\frac{\partial(\rho v)}{\partial y}+\frac{\partial(\rho w)}{\partial z}=0
$$

or

$$
\frac{\partial \rho}{\partial t}+\frac{\partial}{\partial x_{j}}\left(\rho u_{j}\right)=0 .
$$

For a turbulent flow, the momentum equation is:

$$
\begin{aligned}
& \frac{\partial\left(\rho \bar{u}_{i}\right)}{\partial t}+\frac{\partial\left(\rho \bar{u}_{i} \bar{u}_{j}\right)}{\partial x_{j}}=-\frac{\partial p}{\partial x_{i}}+ \\
& +\frac{\partial}{\partial x_{j}}\left[\mu\left(\frac{\partial \bar{u}_{i}}{\partial x_{j}}+\frac{\partial \bar{u}_{j}}{\partial x_{i}}\right)-\rho \overline{u_{i}^{\prime} u_{j}^{\prime}}\right] .
\end{aligned}
$$

The expression in brackets is shear stress. There are two types of shear stress in turbulent flow, laminar flow shear stress and turbulent shear stress. The first term in the bracket, shear stress describes the molecular diffusion. Another turbulent shear stress is a stress caused by fluctuations in velocity. The second term in the bracket indicates stress disorder called Reynolds stress tensor and proves that it is always positive.

In turbulent flow, Reynolds stress is often much greater than the stress caused by molecular viscosity except in areas near the walls. The $\mathrm{k}-\varepsilon$ model is applied to calculate the Reynolds stress tensor. The values of $\mathrm{k}$ and $\varepsilon$ are determined by the following semi-experimental equations:

$$
\begin{aligned}
& \rho \frac{\partial k}{\partial t}+\rho u_{j} k_{, j}=\left(\mu+\frac{\mu_{t}}{\sigma_{t}} k_{, j}\right)_{j}+G+B-\rho \varepsilon, \\
& \rho \frac{\partial \varepsilon}{\partial t}+\rho u_{j} \varepsilon_{, j}=\left(\mu+\frac{\mu_{t}}{\sigma_{t}} \varepsilon_{, j}\right)_{j}+C_{1} \frac{\varepsilon}{k}\left(G+\left(1-C_{3}\right) B-\frac{C_{2}}{C_{1}} \rho \varepsilon\right),
\end{aligned}
$$

where $C_{1}, C_{2}$, and $C_{3}$ are coefficients experimentally determined.

\section{Numerical simulation}

Due to the complexity of the geometry, dimensions and computations, tetrahedral elements with appropriate lengths have been used to generate grid (Fig. 3, a). In this study, because of the complexity of impeller profile and its change over the time, the moving reference frame (MRF) method was used to numerical simulation. The equations of momentum (in three directions $\mathrm{x}, \mathrm{y}, \mathrm{z}$ ), continuity, energy, $k$ and $\varepsilon$ were solved simultaneously. It is worthy to note that $\varepsilon$ and $\mathrm{k}$ are only dependent on the flow and geometry of the impeller. In this study, air is considered as the ideal gas and due to its high speed (more than $100 \mathrm{~m} / \mathrm{s}$ ), it is assumed to be compressible and the integrated system is considered to be adiabatic. Then the effects of air inlet pressure (relative) versus the air outlet pressure (absolute 1 bar) and other parameters (inlet diameter and gap) on the torque, pressure distribution over the blades, the equivalent forces applied to the bearings, air density, and temperature distribution around the blades were studied for three models (Types 1, $2,3)$ and related charts were extracted. Using finite volume method (FVM) and applying the conservation laws, mesh geometry values in places between pieces are calculated. Due to turbulence flow of the dental air turbine flow field, It should be noted that the $\varepsilon$ and $k$ are not made only to the flow and geometry of the gas, since that method of calculation is complex formula to ease the task of Alternative Methods (introduced hydraulic diameter (the diameter of the inlet nozzle) and the intensity of turbulence) were used. To validate the numerical answers should be independent of grid size, time step size and scope of the study and the small amount remaining is laying the groundwork for the accuracy of the numerical solution.

\section{Simulation results}

In this section, the simulation results are presented. All results have been obtained for the constant speed of $250000 \mathrm{rpm}$ which is considered as nominal operating speed. The angle of inlet nozzle is 10 degrees and constant during all simulations.

In this paper, the effect of air inlet pressure on the torque of the headpiece has been studied. The inlet air pressure is increased from 1.5 to 3.5 bars with step of 0.5 bars for three types of cartridges. The results show that the torque increases when the inlet pressure increase in each case. The behavior apparently follows a meaningful pattern (Fig. 4). 


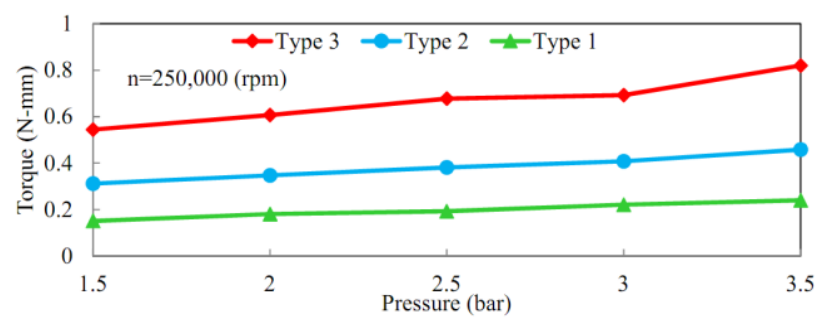

Fig. 4 Torque vs. air inlet pressure

Moreover, the effect of air inlet pressure on applied force to the impeller has been also studied. As in previous case, the inlet pressure increase from 1.5 to 3.5 bars with the step of 0.5 bars and the applied forces to impeller in three directions $\mathrm{x}, \mathrm{y}$, and $\mathrm{z}$ are extracted. It is important to note that the z-component of force (axial component) is much less than two other components and is insignificant and negligible compared to others. This is because of the symmetry conditions of the problem in $\mathrm{z}$ direction. Therefore, two force components in $\mathrm{x}$ and $\mathrm{y}$ directions are depicted in Figs. $5,6,7$. The results show that the total applied force FT is proportional to the air inlet pressure and its behavior is almost linear (Fig. 8). It is obvious that this force must be tolerated by bearings and therefore can be an important factor affecting bearing life and intensification of the adverse effects of fatigue.

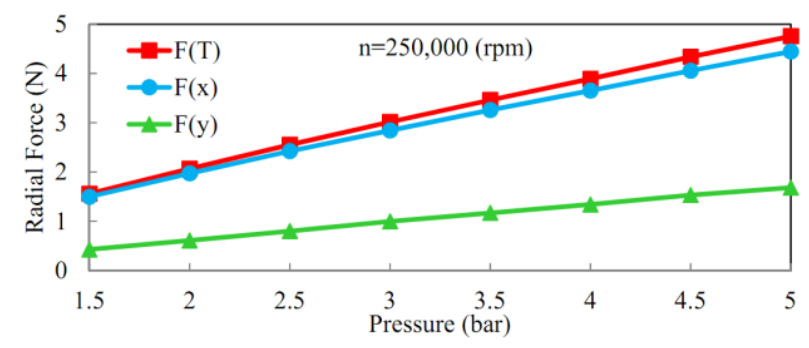

Fig. 5 The radial force (total force and its $\mathrm{x}$ and y components) applied to impeller type 1 vs. air inlet pressure

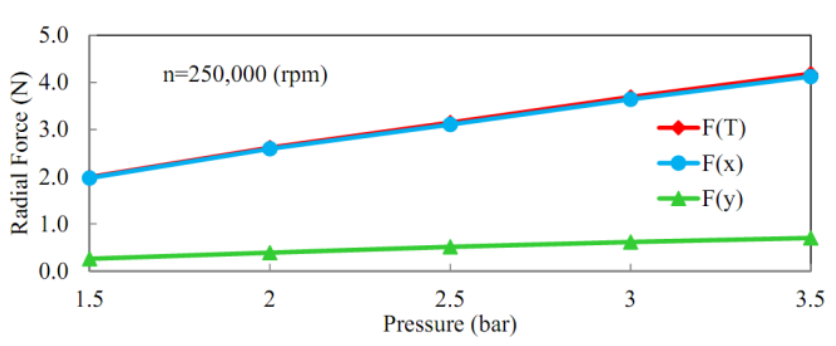

Fig. 6 The radial force (total force and its $\mathrm{x}$ and $\mathrm{y}$ components) applied to impeller type 2 vs. air inlet pressure

Changing of rotational speed is similar to that of previous subsection. In the specified velocity, the pressure distribution within the casing of cartridge for the model Type 2, and its corresponding maximum pressure applied to the impeller was determined (Fig. 3, b). The obtained results show that by increasing the inlet pressure, the maximum pressure is also intensified and always occurs on the blade in opposite of the inlet nozzle (Fig. 9).

Distribution of air temperature in the cartridge is also studied in this article. Changing of rotational speed is again similar to that of previous subsections. In the specified velocity, the temperature distribution within the casing of cartridge for the model Type 2, and its corresponding max-

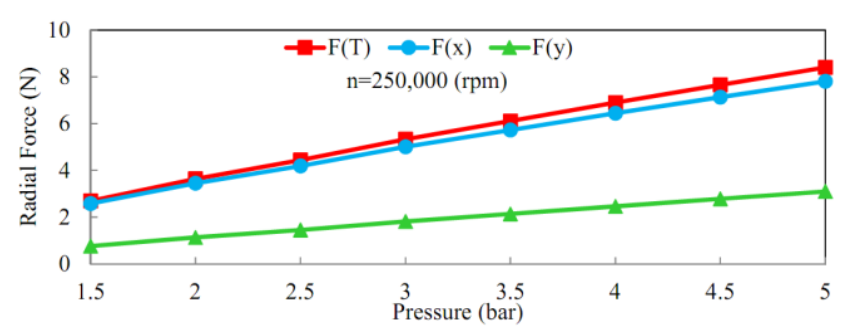

Fig. 7 The radial force (total force and its $\mathrm{x}$ and y components) applied to impeller type 3 vs. air inlet pressure

imum temperature was determined (Fig. 3, c). The results show that the maximum temperature happens in the vicinity of the shell (around the gap). The intensity of the temperature increases when the air approaches the outlet nozzle (Fig. 10).

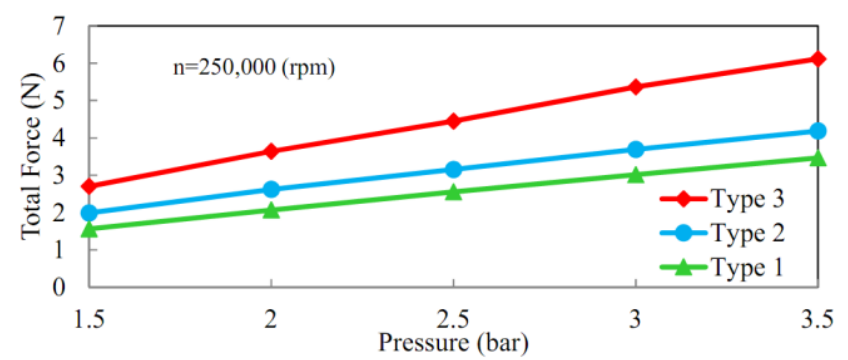

Fig. 8 The radial total forces applied to three types of impeller vs. air inlet pressure

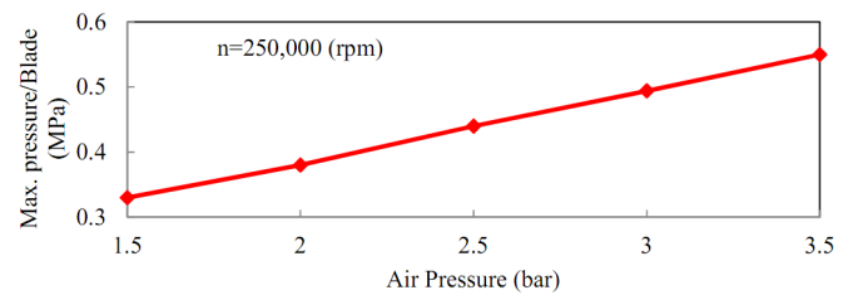

Fig. 9 Maximum air pressure variation on the blade vs. the inlet pressure

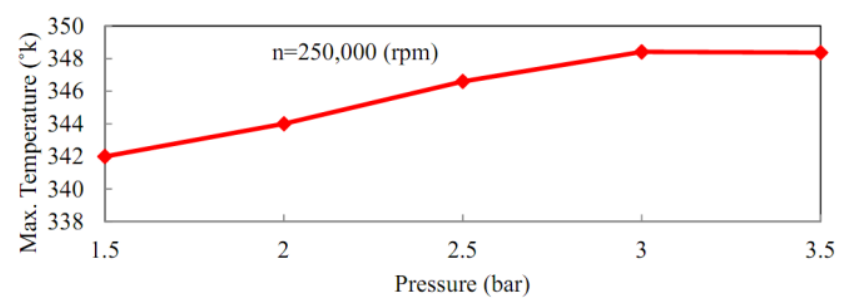

Fig. 10 The maximum air temperature variation in the cartridge vs. inlet pressure

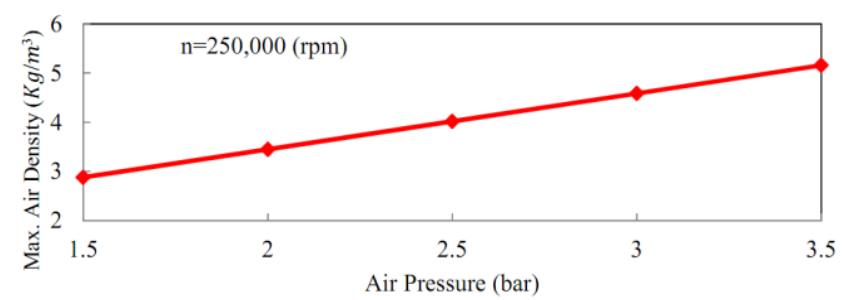

Fig. 11 The maximum air density variation in the cartridge vs. inlet pressure

Air density distribution in the cartridge has been also simulated. Changing of rotational speed is again similar to that of previous subsections. In the specified velocity, the air density distribution within the casing of cartridge for the 
model Type 2, and its corresponding maximum temperature was determined (Fig. 3, d). The results show that with the increase in air pressure, the maximum air density is also aggravated linearly. The maximum density of air occurs around the blade opposite the inlet nozzle (Fig. 11).

Finally, the effect of inlet nozzle diameter on the torque and force of the impeller has been studied. The input pressure and rotational velocity conditions are similar to those of the previous subsection. The diameter of the inlet nozzle varied from 1.5 to $2.5 \mathrm{~mm}$ with the step of $0.25 \mathrm{~mm}$, and thus for the model Type 2, the torque and force applied to the impeller were determined. The study shows that by increasing the diameter of the inlet nozzle, the torque and

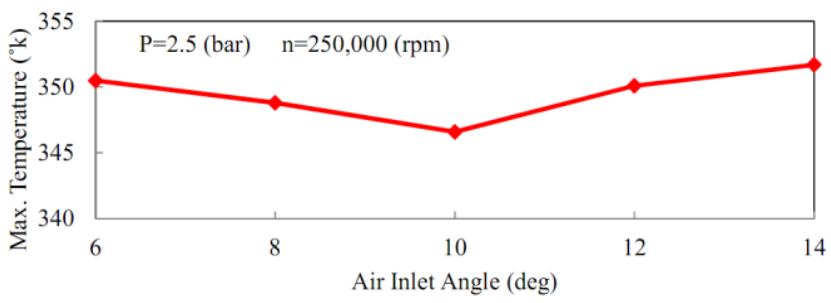

Fig. 12 Max temperature in cartridge for different gaps

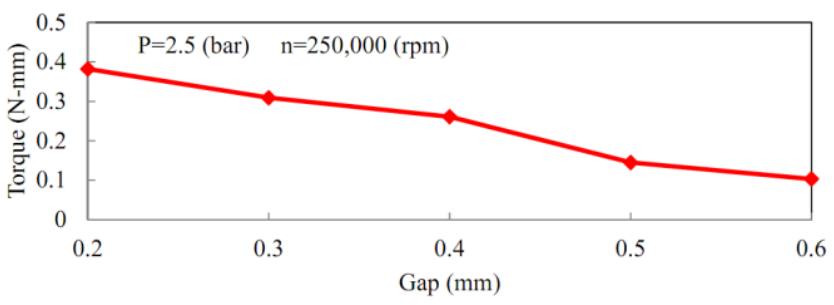

Fig. 13 Generated torque vs. gap

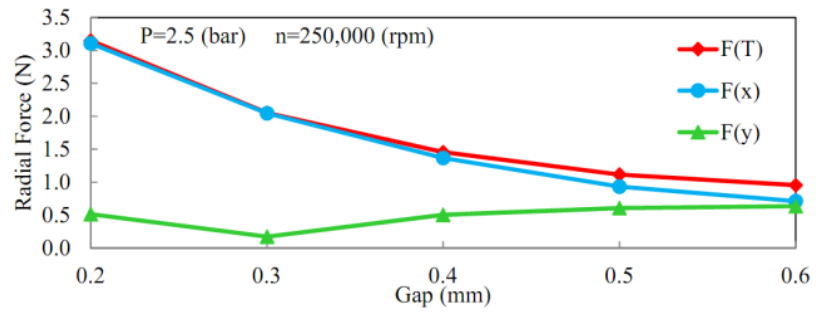

Fig. 14 Applied forces to the impeller vs. gap

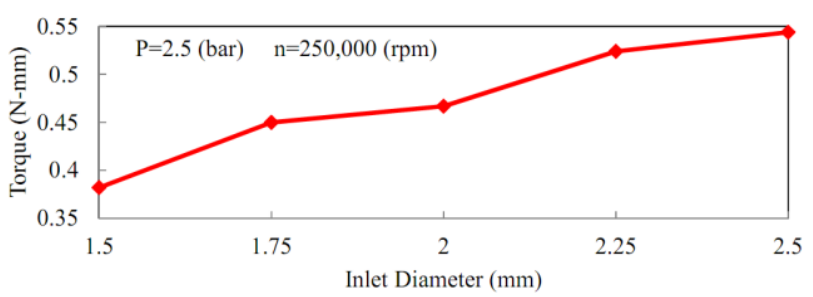

Fig. 15 Generated torque vs. inlet nozzle diameter

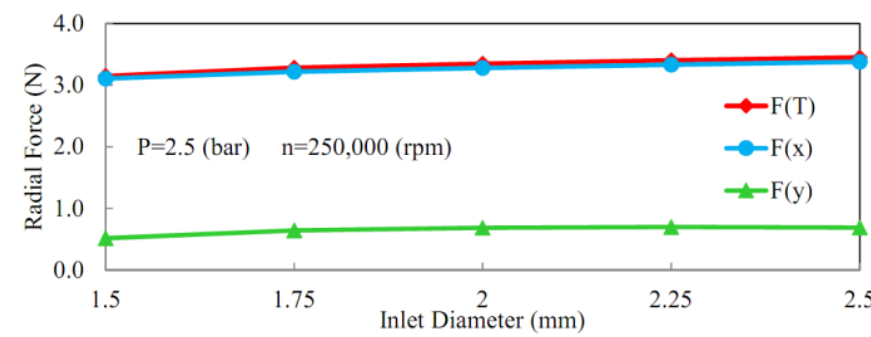

Fig. 16 Applied forces to the impeller vs. inlet nozzle diameter the resultant force increase according to a certain pattern (Fig. 15, 16).

The effect of the gap on the torque, force and temperature distribution within the cartridge has been studied in this article. The simulation was performed for inlet pressure of 2.5 bars and constant rotational velocity of $250000 \mathrm{rpm}$. The gap varied from 0.2 to $0.6 \mathrm{~mm}$ with the step of $0.1 \mathrm{~mm}$, and therefore the torque, force (both applied to the impeller) and temperature distribution in the casing of cartridge corresponding to the model Type 2 were determined (Fig. 3, e and 12). The results demonstrate that by increasing the gap in the specified range, the torque and force reduce according to a certain pattern and the maximum temperature is on the base of the blade against the outlet nozzle (Fig. 13, 14).

\section{Discussion}

The simulation results show that for a given rotational velocity, by increasing the air inlet pressure the torque and applied force to the impeller increases according to a certain pattern. Fig. 4 apparently shows that the torque values and its corresponding variation trends are in good agreement with experimental results in other studies [1] and [9]. Also according to the results it is observed that the $\mathrm{z}$ component of the force could be neglected while the resultant force affected by the $\mathrm{x}$ components significantly. It is clear that the applied force should be tolerated by the bearings. Therefore, due to the high speed operation of the system, any increase in the amount of the force could have a significant impact on bearing life and also aggravate the side effects of fatigue. The resulted forced via simulation are in good agreement with experimental results reported in some previous studies $[16,17]$.

Since the fluid density is affected by the pressure, and because the inlet nozzle has the most pressure, it is expected that the maximum of both pressure and air density happen in front of the air inlet nozzle which could be observed in the results (Fig. 3, b and 9). Also considering the impact of particles of compressed air to the impeller and passage of the fluid through the small gap and the high resistance of this area, it is expected that the temperature of the air gradually increases and the maximum temperature happens in front of the outlet nozzle; simulation results have confirmed these facts. The results show that by increasing the gap, the torque, the applied force to the impeller and the temperature reduce. These results could be interpreted in such a way that by increasing the gap, the resistance of this region against the passage of fluid decreases and the air could flow easily. In the other hand, a portion of fluid that does not perform work over the blade passes the current blade and the does not increase the total torque. Furthermore, the results show that by increasing the diameter of the inlet nozzle and its corresponding angle in the specified ranges, the torque and applied force on the impeller increase. The increasing of nozzle diameter provides the better and uniform conductivity of air. However, it does not dramatically affect the torque of the impeller. It is because when the diameter of the nozzle increases, the velocity of the inlet air decreases and in spite of that, it increases the input flow intensifying the momentum of the inlet air to the system and also in a wider air strikes the blades and increases the torque.

Simulation studies show that at very high speeds, results may not follow this pattern; for example, it has been 
shown that by increasing the nozzle diameter, the torque remains unchanged or even reduces in speeds more than $300000 \mathrm{rpm}$ [12]. Therefore, it is emphasized that the results and figures obtained in this study corresponds to the specified rotational speed and are valid for the aforementioned parameters and conditions; the current results are in good agreement with the previously performed studies $[9,12]$.

\section{Conclusion}

In this study, the effects of air inlet pressure, gap and nozzle diameter on the impeller torque and its applied force in three directions of $\mathrm{x}, \mathrm{y}$, and $\mathrm{z}$ was studied. Moreover, the pressure, temperature and air density distribution within the casing of the cartridge were numerically investigated. Studies showed that by increasing the inlet pressure, torque and resultant force acting on the impeller follow certain patterns. Also, the maximum values of air pressure and density are in the region near the blade wall which is in front of the inlet nozzle and away from this position are reduced. By decreasing the gap, the temperature gradient around of the blade was intensified and the maximum temperature occurred in front of the outlet nozzle. By increasing the inlet nozzle diameter, the torque increased in a specified rotational speed and inlet pressure. Furthermore, the torque and applied forces to the impeller had also an increasing trend with reducing of the cartridge gap.

\section{Acknowledgement}

This research was supported by the grant of Iran National Science Foundation (INSF-93037216).

\section{References}

1. Brockhurst, P.J.; Shams, R. 1994. Dynamic measurement of the torque-speed characteristics of dental high speed air turbine handpieces, Australian dental journal 39(1):33-8.

http://dx.doi.org/10.1111/j.1834-7819.1994.tb05544.x.

2. Alrahabi, M.; Zafar, M.S.; Ahmed, N. 2015. Effects of handpiece speed on the performance of undergraduate dental students in preclinical training, Journal of Taibah University Medical Sciences 10(1):50-55. http://dx.doi.org/10.1016/j.jtumed.2014.12.005.

3. Shamami, D.Z.; Karimi, A.; Beigzadeh, B.; Derakhshan, S.; Navidbakhsh, M. 2014. A three-dimensional finite element study to characterize the influence of load direction on stress distribution in bone around dental implant, Journal of Biomaterials and Tissue Engineering 4(9):693-699.

http://dx.doi.org/10.1166/jbt.2014.1230.

4. Shamami, D.Z.; Karimi, A.; Beigzadeh, B.; Haghpanahi, M.; Navidbakhsh, M 2014. A 3D finite element study for stress analysis in bone tissue around single implants with different materials and various bone qualities. Journal of Biomaterials and Tissue Engineering 4(8):632-637.

http://dx.doi.org/10.1166/jbt.2014.1212.

5. Juraeva, M.; Ryu, K.J.; Song, D.J. 2014. Optimum design of a saw-tooth-shaped dental air-turbine using design of experiment, International journal of precision engineering and manufacturing 15(2):227-234. http://dx.doi.org/10.1007/s12541-014-0329-6.
6. Dyson, J.E.; Darvell, B.W. 1999. Flow and free running speed characterization of dental air turbine handpieces, Journal of dentistry 27(7):465-77.

http://dx.doi.org/10.1016/S0300-5712(99)00037-8.

7. Dyson, J.E.; Darvell, B.W 1995. Dental air turbine handpiece performance testing, Australian Dental Journal 40(5):330-338.

http://dx.doi.org/10.1111/j.1834-7819.1995.tb04823.x.

8. Poole, R.L.; Lea, S.C.; Dyson, J.E., Shortall, A.C.; Walmsley A.D. 2008. Vibration characteristics of dental high-speed turbines and speed-increasing handpieces, Journal of Dentistry 36(7):488-493. http://dx.doi.org/10.1016/j.jdent.2008.03.006.

9. Seto, W.C. 2004. Design factors affecting air turbine handpiece Performance, The University of Hong Kong https://doi.org/10.5353/th_b3195438.

10. Muller, C.; Reichenbach, I.G.; Aurich, J.C. 2014. Design and numerical simulation of an air turbine for a high frequency tool spindle, ICOMM 2014, No. 30.

11. Chiang, H.W.; Hsu, C.N.; Chang, Y.Y.; Chuang, S.Y. 2010. Dental Air Turbine Performance Study Using CFD and Experimental Approach. In ASME Turbo Expo 2010: Power for Land, Sea, and Air. pp. 13251332. https://doi.org/10.1115/GT2010-23039.

12. Hsu, C.N.; Chiang, H.W.; Chang, Y.Y. 2011. Numerical Simulation and Experimental Study of a Dental Handpiece Air Turbine, International Journal of Turbo and Jet Engines 28(2):159-68. http://dx.doi.org/10.1515/tjj.2011.016.

13. Wei, M.; Dyson, J.E.; Darvell, B.W. 2012. Factors affecting dental air-turbine handpiece bearing failure, Operative Dentistry 37(4):1-12. http://dx.doi.org/10.2341/11-087-L.

14. Derakhshan, S.; Tavaziani, A.; Kasaeian, N. 2015. Numerical shape optimization of a wind turbine blades using artificial bee colony algorithm. Journal of Energy Resources Technology 137(5):051210. http://dx.doi.org/10.1115/1.4031043.

15. Highspeed Handpiece Design, American Dental Accessories, [accessed 15 May 2016]. Available from Internet: http://www.amerdental.com/blog/tech-tips-22/.

16. Elias, K.; Amis, A.A.; Setchell, D.J. 2003. The magnitude of cutting forces at high speed, The Journal of prosthetic dentistry 89(3):286-91. http://dx.doi.org/10.1067/mpr.2003.35.

17. Song, X.F.; Yin, L.; Peng, J.H.; Lin, B. 2013. Cutting characteristics of dental glass ceramics during in vitro dental abrasive adjusting using a high-speed electric handpiece, Ceramics International 39(6):6237-6249. http://dx.doi.org/10.1016/j.ceramint.2013.01.045.

\section{B. Beigzadeh, S. Derakhshan, D. Zia Shamami}

\section{A NUMERICAL STUDY ON PERFORMANCE OF DENTAL AIR TURBINE HANDPIECES}

S u m m a r y

In the present work, the original dental air turbine handpieces were disassembled and their parts were modeled using reverse engineering. Then, simulation of dental cartridge was performed and the effect of different parameters 
was investigated. In dental air turbines, the flow channel and blade shape have major influence on the torque, rotating speed, and power performance. This research is focused on the turbine impeller and flow channel diameter. For this aim, three types of dental cartridges with different blades, nozzle diameter and the gap size between air turbine and casing were analyzed. The effect of air inlet pressure on torque, total force, air density and temperature distribution were investigated using computational fluid dynamic (CFD) simulation and related graphs were extracted. The results showed the turbine impeller designs including impeller diameter and blade shape can have major impacts on the torque and performance.

Keywords: dental handpiece, high speed air turbine, CFD.

Received July 05, 2016

Accepted October 13, 2017 